\title{
Perceived stigma and associated factors among adults with problematic substance use in Northwest Ethiopia
}

\author{
Habte Belete iD ${ }^{\prime}$ \\ Tilahun Ali (D) ${ }^{2}$ \\ Tesfa Mekonen (iD \\ Wubalem Fekadu (iD) \\ Tilahun Belete' \\ 'Psychiatry Department, College of \\ Medicine and Health Sciences, Bahir Dar \\ University, Bahir Dar, Ethiopia; \\ ${ }^{2}$ Department of Psychiatry, School of \\ Nursing and Midwifery, College of Health \\ and Medical Sciences, Haramaya \\ University, Harar, Ethiopia
}

Background: Substance use-related problems including cigarette smoking and alcohol use are among leading preventable risk factors for premature death. However, people with these problems did not get the appropriate treatment they need. Stigma against substance use could be the potential barrier for people with problematic substance use to seek professional help. Therefore, the objective of this study was to investigate magnitude and associated factors of perceived stigma towards problematic substance use.

Methods: A total of 2400 participants were screened using the Cut down, Annoyed, Guilty, and Eye-opener (CAGE) Adapted to Include Drugs (CAGE-AID) questionnaire. We found 540 participants screened positive for problematic substance use (alcohol, hashish, tobacco and khat) and interviewed them for perceived stigma using Perceived Stigma of Substance Abuse Scale (PSAS). Logistic regression was used to examine associated factors with perceived stigma.

Results: Three hundred forty-five (63.9\%) participants reported perceived stigma above the mean value of Perceived Stigma of Substance Abuse Scale (PSAS). Variables positively associated with perceived stigma were lower wealth and joblessness, history of separation from family members before age of 18 years, poly-substance misuse and awareness about economic crisis of substance use.

Conclusion: Approximately, three in five people with problematic substance use perceived having been stigmatized by others. Health planning for problematic substance use should focus on stigma.

Keywords: perceived stigma, problematic substances use, urban, Ethiopia, low-income

\section{Introduction}

Perceived stigma is fear of being discriminated against or the fear of enacted stigma and arises from society's belief. ${ }^{1}$ Perceived stigma among individuals with problematic substance use creates a cyclic impact on social isolation, marginalization, and links with addiction relapse. This complexity potentiates stigma against problematic substance use in the community and delayed efforts towards prevention and control of other substance-related medical and mental disorders. ${ }^{2}$ Although most of negative mental health outcomes could be prevented, stigma and discrimination remains as a critical challenge in mental health systems. ${ }^{3}$ Alcohol and khat (a green stimulant leaf) use are common practice among adults and adolescents in Ethiopia. ${ }^{4,5}$

Problematic substance use (PSU) includes situations in where the use of a substance negatively impacts the ability of an individual overall functioning.
Correspondence: Tilahun Ali

Department of Psychiatry, School of Nursing and Midwifery, College of Health and Medical Sciences, Haramaya

University, Harar, Ethiopia

Email tilahun1989@gmail.com 
Regardless of the initiation of treatment for problematic substance use, there is a strong and enduring effect of stigma on mental well-being. Stigma continues to complicate lives of the stigmatized individuals even as treatment improves their symptoms and functioning. ${ }^{6}$ In mental health care, stigma related to problematic substance use is associated with multiple negative social outcomes such as involvement with the criminal justice system, ${ }^{7,8}$ difficulty in employment, ${ }^{9,10}$ social adjustment problems, ${ }^{11,12}$ psychological distress, ${ }^{13}$ and poor community judgment. ${ }^{14,15}$ When individuals suffer from stigma due to their problematic substance use, they may face a problem to receive community-based services. ${ }^{7}$ Substance use-related stigma has also affect the clinical population $^{16}$ that leads to rejection ${ }^{17}$ in the community and delays in treatment seeking behavior. ${ }^{18}$

Stigma towards a problematic substances use exceeds $60 \%$ in the USA, ${ }^{10,19,20}$ and $22.1 \%$ in developing countries among psychiatric patients. ${ }^{21}$ In a larger population-based study in the UK, up to $78 \%$ of participants believed that individuals with alcohol and drug addiction are dangerous and unpredictable. ${ }^{22}$ In the USA, $86.1 \%$ of participants had suffered from perceived stigma for their risky drinking. ${ }^{14}$ There is a report of $58.1 \%$ perceived stigma among psychiatric patients who use substance in Ethiopia. ${ }^{23}$ Even health professionals stigmatized individuals with a problematic substance use, and those professionals has perceived violence, manipulation, and poor motivation as impeding factors in the healthcare delivery for these patients. ${ }^{24}$ Numerous factors have been reported to be associated with perceived stigma including lower education, being married/living with someone and being unemployed; ${ }^{25}$ greater social interaction, rural resident; ${ }^{14}$ lower self-esteem, higher behavioral disturbance, ${ }^{26}$ gender, and income. ${ }^{27}$

Despite the high magnitude and impacts of stigma among individuals with problematic substance use reported in the developed world, still there is no well-stated information in low-income settings like Ethiopia concerned to stigma for problematic substance use. Therefore, the aim of this study was to assess the magnitude of perceived stigma and associated factors among individuals with problematic substance use in urban community.

\section{Methods}

\section{Design and Setting}

A community-based cross-sectional survey was conducted at Bahir Dar town, northwest Ethiopia. Bahir Dar has a total of 180,174 populations; of these 87,160 are males. There are three public and three private hospitals, and ten health centers.

\section{Participant Selection and Data Collection}

We have selected participants in two-stage process. First, we screened a total of 2400 adults in the community for problematic substance use using CAGE-AID questionnaire. Five hundred forty of them fulfilled criteria of problematic substance use (Khat, alcohol, tobacco, and cannabis). Secondly, we have interviewed 540 individuals for perceived stigma. Data were collected by degree holder nurses with face-to-face interviews using a semi-structured questionnaire which was translated into Amharic version (local working language).

\section{Instruments}

CAGE-AID: The CAGE-AID questionnaire has been used to assess problematic substance use. CAGE-AID is derived from the original CAGE (Cut down, Annoyed, Guilty, and Eye-opener) to include alcohol and other substances, with yes or no responses which account a total of four points. CAGE-AID helps to screen the presence of problematic substances use among adults in the community. Scoring of two or more positive answers for alcohol and other substances (hashish, tobacco and khat) was considered as problematic substance use. ${ }^{28}$ The CAGEAID screening has been pretested, and it has good internal consistency $(\alpha=0.78)$.

PSAS: The Perceived Stigma of Substance Abuse Scale (PSAS) has been used to assess the individual perception about being substance user in the community and the perceived stigmatization. PSAS has 8 items with fourpoint likert-scale from "strongly disagree" to "strongly agree". The total score ranges from 8 to 32; scores higher than the mean indicated greater perceived stigma. ${ }^{29,30}$

OSSS: The participants' social support was assessed with Oslo Social Support Scale, which consists three items. $^{31}$

Perceived relative wealth: was assessed by simply asking participants what they perceived about their wealth to be in relation to other people in the neighborhood (poor, average or well-off) and participants were asked to level their own income by comparing with others as less than others; similar to others and better than others. Following previously published work, ${ }^{32,33}$ we applied the method of principal component analysis to these variables. 
Educational status was categorized in uneducated (who were unable to read and write); and educated (which were able to read and write). Comorbid medical illnesses were assessed by self-report of the participants if they had been diagnosed with medical problems.

\section{Data Quality Control}

The questionnaire was prepared in English and then translated into Amharic for data collection and re-translated back into English by language experts. Two days training was provided to the data collectors and supervisors on the data collection tools and the data collection procedures. After that, the questionnaire was pre-tested on $5 \%$ of the sample size out of the study area to ensure its validity. Data collectors were closely supervised by supervisors and the principal investigator. Completeness of each questionnaire was checked on a daily basis. Double data entry was done by two data clerks, and consistency of the entered data was cross-checked by comparing the two separately entered data.

\section{Data Processing and Analysis}

The collected data were checked for its completeness and cleaned before entry into computer. Then, data were coded, cleaned, edited, and entered into EpiData version 3.1 and exported to SPSS window version 20 for analysis. Descriptive statistics were presented in frequency, tables, texts and summary measures.

Bivariate and multivariate analysis were done to see the association between each independent variable and outcome variable by using binary logistic regression. The assumption for binary logistic regression were checked. All variables with $\mathrm{p}<0.25$ in the bivariate analysis was included in the final model of multivariate analysis in order to control all possible confounders. The direction and statistical association were measured by odds ratio with 95\% CI. Adjusted odds ratio along with $95 \% \mathrm{CI}$ was estimated to identify associated factors with perceived stigma for a problematic substance use by using multivariate analysis in binary logistic regression. In this study, $\mathrm{P}$-value $<0.05$ were considered to declare a statistically significant.

\section{Ethics Approval and Consent to Participate}

Ethical approval was obtained from an Institutional Health Research Ethics Review Committee (IRB) of Bahir Dar University and ethical clearance was granted. In addition, support letter was written to different stakeholders of the city administrative. The objective and purpose of the study were verified briefly to all of the study participant and confidentiality was assured. Finally, written consent was obtained from study participants before conducting the interview. Participants with problematic substance use during the screening were referred to clinic for better screening. This study was conducted in accordance with the Declaration of Helsinki.

\section{Results}

From 540 participants, 415 (76.9\%) were males. The mean age of participant was 29.78 years (Standard Deviation $=9.82$ years), and most of participants 399 (73.9\%) were currently unmarried (Table 1).

Of the total participants, $240(44.4 \%)$ of them were thinking that treatment is not needed for their substancerelated behavioral disturbances. However, 389 (72\%) of them were aware about the problematic substance userelated economic crisis in their life (Table 2).

\section{Magnitude of Perceived Stigma}

About $63.9 \%$ (95\% CI: 60-68\%) of participants scored above the mean on PSAS. Mean values revealed that 195 (36.1\%) had low-perceived stigma (score of $<2.5$ points) and the rest $(n=345,63.9 \%)$ had a high perceived stigma score ( $\geq 2.5$ points).

Of the total participants who reported perceived stigma, 279 (80.87\%) were khat users, and $213(61.7 \%)$ poly-substance users (Table 3 ).

\section{Factors Associated with Perceived Stigma}

All variables were processed on bivariate analysis and ten variables (sex, wealth, job, history of separation from family before age of 18 years, poly-substance misuse, social support, and awareness about the economic crisis of substance use were found to be significant and consider for multiple logistic regression. Finally, after multivariable logistic regression analysis of perceived stigma in relation to all independent variables; lower wealth, joblessness, history of separation from the family before the age of 18 years old, polysubstance misuse, and awareness about the economic crisis of substance use were found to be statistically significant (Table 4).

\section{Discussion}

Perceived stigma among individuals with a problematic substance use is the main risk factor that contributing to 
Table I Socio-Demographic Characteristics Related to Perceived Stigma Among Individuals with Problematic Substance Use ( $\mathrm{n}=540)$

\begin{tabular}{|c|c|c|c|c|}
\hline \multirow[b]{2}{*}{ Characteristics } & \multicolumn{2}{|c|}{ Perceived Stigma } & \multirow[b]{2}{*}{ Overall (\%) } & \multirow[b]{2}{*}{ Chi-Square Test $\left(\mathbf{X}^{2}\right)(\mathrm{p}$-value $)$} \\
\hline & Yes & No & & \\
\hline \multicolumn{5}{|l|}{ Sex } \\
\hline Male & 254 & 161 & $415(76.9 \%)$ & $5.6(0.02)$ \\
\hline Female & 91 & 34 & $125(23.1 \%)$ & \\
\hline \multicolumn{5}{|c|}{ Current marital status } \\
\hline Married & 97 & 44 & $|4|(26.1 \%)$ & $1.9(0.16)$ \\
\hline Unmarried & 248 & 151 & $399(73.9 \%)$ & \\
\hline \multicolumn{5}{|l|}{ Relative wealth } \\
\hline Lower & 132 & 93 & $225(41.7 \%)$ & $5.1(0.07)$ \\
\hline Same & 177 & 81 & $258(47.8 \%)$ & \\
\hline Better & 36 & 21 & 57 (10.6\%) & \\
\hline \multicolumn{5}{|l|}{ Job } \\
\hline Having job & 149 & 149 & $298(55.2 \%)$ & $55.6(0.000 \mathrm{I})$ \\
\hline Jobless & 196 & 46 & $242(44.8 \%)$ & \\
\hline \multicolumn{5}{|c|}{ Living circumstance } \\
\hline With family & 198 & 104 & 302 (55.9\%) & $0.83(0.36)$ \\
\hline Alone & 147 & 91 & $238(44.1 \%)$ & \\
\hline
\end{tabular}

Table 2 Psychosocial Factors Related to Perceived Stigma Among Individuals with Problematic Substance Use $(n=540)$

\begin{tabular}{|c|c|c|c|c|}
\hline \multirow[b]{2}{*}{ Characteristics } & \multicolumn{2}{|c|}{ Perceived Stigma } & \multirow[b]{2}{*}{ Overall (\%) } & \multirow[b]{2}{*}{$\begin{array}{l}\text { Chi-square test }\left(\mathbf{X}^{2}\right)(p- \\
\text { value) }\end{array}$} \\
\hline & Yes & No & & \\
\hline \multicolumn{5}{|c|}{ History of separation from family before age of 18 years } \\
\hline Yes & 116 & 40 & I56 (28.9\%) & $10.4(0.001)$ \\
\hline No & 229 & 155 & $384(71.1 \%)$ & \\
\hline \multicolumn{5}{|c|}{ Who had substance user family members? } \\
\hline Yes & 99 & 57 & I56 (28.9\%) & $0.02(0.89)$ \\
\hline No & 246 & 138 & $384(71.1 \%)$ & \\
\hline \multicolumn{5}{|c|}{ Who had substance user friend? } \\
\hline Yes & 121 & 80 & $201(37.2 \%)$ & $1.9(0.17)$ \\
\hline No & 224 & 115 & $339(62.8 \%)$ & \\
\hline \multicolumn{5}{|c|}{ Comorbid medical illnesses } \\
\hline Yes & 43 & 25 & $68(12.6 \%)$ & $0.01(0.9)$ \\
\hline No & 302 & 170 & $472(87.4 \%)$ & \\
\hline \multicolumn{5}{|c|}{ Awareness about substance use leads economic crisis } \\
\hline Yes & 232 & 157 & $389(72 \%)$ & $10.9(0.001)$ \\
\hline No & 113 & 38 & I5I (28\%) & \\
\hline \multicolumn{5}{|l|}{ Social support } \\
\hline Poor & 108 & 92 & $200(37 \%)$ & I4.I (0.00I) \\
\hline Moderate & 193 & 80 & $273(50.6 \%)$ & \\
\hline Good & 44 & 23 & 67 (I2.4\%) & \\
\hline
\end{tabular}


Table 3 Association Between Type of Substance Use and Perceived Stigma Among Individuals with Problematic Substance Use $(n=540)$

\begin{tabular}{|c|c|c|c|c|}
\hline \multirow[b]{2}{*}{ Characteristics } & \multicolumn{2}{|c|}{ Perceived Stigma } & \multirow[b]{2}{*}{ Overall (\%) } & \multirow[b]{2}{*}{$\begin{array}{l}\text { Chi-square test }\left(X^{2}\right)(p \\
\text { value) }\end{array}$} \\
\hline & Yes & No & & \\
\hline \multicolumn{5}{|l|}{ Hashish } \\
\hline Yes & 78 & 73 & I5I (28\%) & $13.6(0.000 \mid)$ \\
\hline No & 267 & 122 & 389 (72\%) & \\
\hline \multicolumn{5}{|l|}{ Khat } \\
\hline Yes & 279 & 145 & $424(78.5 \%)$ & $3.1(0.077)$ \\
\hline No & 66 & 59 & $384(21.5 \%)$ & \\
\hline \multicolumn{5}{|l|}{ Tobacco } \\
\hline Yes & 144 & 123 & 267 (49.4\%) & $22.7(0.0001)$ \\
\hline No & 201 & 72 & $273(50.6 \%)$ & \\
\hline \multicolumn{5}{|l|}{ Alcohol } \\
\hline Yes & 220 & 164 & $384(71.1 \%)$ & $25.1(0.0001)$ \\
\hline No & 125 & 31 & 159 (28.9\%) & \\
\hline \multicolumn{5}{|c|}{ Number of substance use } \\
\hline Poly-substance & 213 & 154 & 367 (68\%) & $16.9(0.0001)$ \\
\hline Mono-substance & 132 & 41 & $173(32 \%)$ & \\
\hline
\end{tabular}

unmet need for treatment of problematic substance use. ${ }^{34}$ Individuals with problematic substance use might be stigmatized $^{35}$ in the process of their in-adherence to the normative social expectations in the social network.

About $63.9 \%$ of participants of this study scored above the mean of the PSAS tool. This high perceived stigma might decrease the intention of help seeking behavior and delays in treatment seeking behavior in this population. ${ }^{18}$ Not seeking help early due to this stigma may also result further health complication including dependency and comorbidity, and economic-related crisis. ${ }^{2,3}$

The prevalence of perceived stigma is higher in this study which compared to in developed countries, $14.8 \%{ }^{25}$ but lower than $86.1 \%$ in Little Rock, Arkansas, ${ }^{14} 90 \%$ in alcoholic women in Michigan, USA, ${ }^{20} 58.1 \%$ in Ethiopia among psychiatric patients who use substance. ${ }^{23}$ For this discrepancy, factors like social sensitivity for substance use, cultural pattern for substance use, methodological differences and socio-cultural factors might be responsible.

Joblessness $(\mathrm{AOR}=4.92,95 \% \mathrm{CI}=3.19,7.60)$ and lower wealth $(\mathrm{AOR}=1.70,95 \% \mathrm{CI}=1.09,2.65)$ had a significant association with perceived stigma. As WHO report points out that the economic crises had a negative mental health outcomes ${ }^{3}$ and substance use interferes with the effectiveness of once work, reduce the potential of productivity and can be contributed for perceived stigma among problematic substance users. Spending time without any job and without contribution to the families and the society at large has a negative psychological impact among problematic substance users. ${ }^{36,37}$ Perceived stigma may be triggered not only by being joblessness, but also being economical dependent on the family ${ }^{25}$ and low income. ${ }^{27}$ Participants' awareness about the economic crisis of substance use had a significant association with stigma $(\mathrm{AOR}=$ $2.29,95 \% \mathrm{CI}=1.43,3.66)$. Individuals who use substance always need more money for their substance use and to get this money, they may need supports from others in which may results stigmatization. This finding was supported by previous studies in which perceived stigma for problematic substance use had implication for unemployment. ${ }^{9,10}$ Problematic substances use had a substantial contribution for poor motivation of working that resulted low rate of employment and leads stigmatization in the community. ${ }^{38}$

History of separation from family members before age of 18 years old $(\mathrm{AOR}=2.00,95 \% \mathrm{CI}=1.27,3.16)$ had significant association with perceived stigma among individuals with problematic substances users. Separation from intimate family during childhood is risk for various social problems, sexual, psychological and physical abuses and contributions for experimenting of substance at early 
Table 4 Factors Association with Perceived Stigma Among Individuals with Problematic Substance Use $(n=540)$

\begin{tabular}{|c|c|c|c|c|c|}
\hline \multirow[t]{2}{*}{ Variables } & \multicolumn{2}{|c|}{$\begin{array}{l}\text { Perceived } \\
\text { Stigma }\end{array}$} & \multirow[t]{2}{*}{$\begin{array}{l}\text { Crude Odds Ratio (COR) (95\% } \\
\text { Cl) }\end{array}$} & \multirow[t]{2}{*}{ AOR $(95 \% \mathrm{Cl})$} & \multirow[t]{2}{*}{ p-value } \\
\hline & Yes & No & & & \\
\hline \multicolumn{6}{|l|}{ Wealth } \\
\hline Lower & 132 & 93 & $1.5(1.06,2.24)$ & $1.70(1.09,2.65)^{*}$ & 0.019 \\
\hline Same & 177 & 81 & $1.2(0.66,2.20)$ & $1.96(0.99,3.86)$ & 0.050 \\
\hline Higher & 36 & 21 & 1.00 & 1.00 & \\
\hline \multicolumn{6}{|l|}{ Sex } \\
\hline Male & 254 & 161 & $1.7(1.09,2.63)$ & $1.13(0.68,1.86)$ & 0.636 \\
\hline Female & 91 & 34 & 1.00 & 1.00 & \\
\hline \multicolumn{6}{|l|}{ Job } \\
\hline Has job & 149 & 149 & 1.00 & 1.00 & $<0.0001$ \\
\hline No job & 196 & 46 & $4.3(2.87,6.31)$ & $4.92(3.19,7.60)^{*}$ & \\
\hline \multicolumn{6}{|c|}{ Childhood separation } \\
\hline Yes & 116 & 40 & $1.96(1.29,2.97)$ & $2.00(1.27,3.16)^{*}$ & 0.003 \\
\hline No & 229 & 155 & 1.00 & 1.00 & \\
\hline \multicolumn{6}{|c|}{ Number of substance use } \\
\hline Poly-substance & 213 & 154 & $2.33(1.55,3.49)$ & $\begin{array}{l}2.04(1.29,3.24) \\
*\end{array}$ & 0.002 \\
\hline Mono-substance & 132 & 41 & 1.00 & 1.00 & \\
\hline \multicolumn{6}{|c|}{$\begin{array}{l}\text { Awareness about substance use leads economic } \\
\text { crisis }\end{array}$} \\
\hline Yes & 232 & 157 & $2.01(1.32,3.06)$ & $2.29(1.43,3.66)^{*}$ & 0.001 \\
\hline No & 113 & 38 & 1.00 & 1.00 & \\
\hline \multicolumn{6}{|l|}{ Social support } \\
\hline Poor & 108 & 92 & $2.06(\mathrm{I} .40,3.0 \mathrm{I})$ & $\mathrm{I} .78(0.93,3.4 \mathrm{I})$ & 0.053 \\
\hline Moderate & 193 & 80 & $1.63(0.92,2.90)$ & $1.54(0.99,2.38)$ & 0.084 \\
\hline Good & 44 & 23 & 1.00 & 1.00 & \\
\hline
\end{tabular}

Note: *(Significance at $\mathrm{P}$ value $<0.05$ ) and 1.00 (reference group).

age in adolescents. ${ }^{12}$ Early engagement in problematic substance use among adolescents has severe behavioral problems and can leads them to be stigmatize in the society within various life aspects. Childhood developmental misbehaviors had remarkable contribution for the behavior of once adulthood and a potential association with problematic substance use across their life-span. It is well known about families support to prevent from psychosocial stressful situations and has a substantial contribution for prevention once child from problematic substance use and discrimination or stigma. ${ }^{15,39}$

Poly-substance misuse had a stronger association with perceived stigma $(\mathrm{AOR}=2.04,95 \% \mathrm{CI}=1.29,3.24)$ than mono-substance misuse. Of course individuals with poly- substance misuse may have face different psychosocial discrimination in the community ${ }^{40,41}$ and may be experience rejection with various aspects of the social system and leads them feel stigmatized in their life span. ${ }^{14}$ Some individuals who take additional illicit drugs such as cannabis may face the threat of legal sanctions and experiences of marginalization (stigma) in the community. ${ }^{17}$

\section{Limitation}

This study has several limitations that should be considered in the interpretation. We cannot report about substance use disorders as we have used a screening tool. Due to the sensitivity issue of substance use, particularly for illicit drugs (cannabis), results might be underestimated as a result of social desirability 
bias. We did not consider the design effect during sampling procedure. Hence, readers need to consider those limitations for this paper.

\section{Implications for Research and Practice}

This examined the magnitude of perceived stigma toward problematic substance use and found a high magnitude in urban population in Northwest Ethiopia. This will help for problematic substance use prevention policy-makers and urban health extension workers to decrease substance-related stigma and to prevent risks of stigma in the community.

\section{Conclusion}

Perceived stigma for problematic substance use was common in urban populations in this study. Stigma found contributed by modifiable risk factors and can be preventable in urban community. Awareness about normalization for substance use in the community is important to decrease the burden of perceived stigma among individuals with a problematic substance use and future prevention of problematic substance use in the community.

\section{Abbreviations}

AOR, adjusted odds ratio; CAGE, Cut down, Annoyed, Guilty, and Eye-opener; CI, confidence interval; SPSS, Statistical Package for Social Science; PSAS, Perceived Stigma of Substance Abuse Scale; WHO, World Health Organization.

\section{Data Sharing Statement}

The datasets used and analyzed in the current study are included within the article.

\section{Acknowledgments}

We acknowledge study participants for their genuine participations.

\section{Author Contributions}

$\mathrm{HB}, \mathrm{TA}, \mathrm{TM}, \mathrm{WF}$ and TB were involved in the conception and design of the study, acquisition of data, analysis and interpretation of data, drafting and revising the article, agreed to submit to the current journal, gave final approval of the version to be published and agree to be accountable for all aspects of the work.

\section{Funding}

There is no funding to report.

\section{Disclosure}

The authors reported no conflicts of interest for this work.

\section{References}

1. LeBel TP. Perceptions of and responses to stigma. Sociol Compass. 2008;2(2):409-432. doi:10.1111/j.1751-9020.2007.00081.x

2. Deng R, Li J, Sringernyuang L, Zhang K. Drug abuse, HIV/AIDS and stigmatisation in a Dai community in Yunnan, China. Soc Sci Med. 2007;64(8):1560-1571. doi:10.1016/j.socscimed.2006.12.011

3. World Health Organization. Impact of economic crises on mental health; 2011

4. Gebrehanna E, Berhane Y, Worku A. Khat chewing among Ethiopian University Students-a growing concern. BMC Public Health. 2014;14 (1):1198. doi:10.1186/1471-2458-14-1198

5. Mulugeta Y. Khat chewing and its associated factor among college students in Bahir Dar Town, Ethiopia. Sci J Public Health. 2013;1 (5):209-214. doi:10.11648/j.sjph.20130105.14

6. Link BG, Struening EL, Rahav M, Phelan JC, Nuttbrock L. On stigma and its consequences: evidence from a longitudinal study of men with dual diagnoses of mental illness and substance abuse. J Health Soc Behav. 1997;38(2):177-190. doi:10.2307/2955424

7. Hartwell S. Triple stigma: persons with mental illness and substance abuse problems in the criminal justice system. Crim Justice Policy Rev. 2004;15(1):84-99. doi:10.1177/0887403403255064

8. Cheng C-M, Chang -C-C, Wang J-D, Chang K-C, Ting S-Y, Lin C-Y. Negative impacts of self-stigma on the quality of life of patients in methadone maintenance treatment: the mediated roles of psychological distress and social functioning. Int $J$ Environ Res Public Health. 2019;16(7):1299. doi:10.3390/ijerph16071299

9. Ettner SL, Huang D, Evans E, et al. Benefit-cost in the California treatment outcome project: Does substance abuse treatment "pay for itself"? Health Serv Res. 2006;41(1):192-213. doi:10.1111/j.14756773.2005.00466.x

10. Luoma JB, Twohig MP, Waltz T, et al. An investigation of stigma in individuals receiving treatment for substance abuse. Addict Behav. 2007;32(7):1331-1346. doi:10.1016/j.addbeh.2006.09.008

11. Perlick DA, Rosenheck RA, Clarkin JF, et al. Stigma as a barrier to recovery: adverse effects of perceived stigma on social adaptation of persons diagnosed with bipolar affective disorder. Psychiatr Serv. 2001;52(12):1627-1632. doi:10.1176/appi.ps.52.12.1627

12. Phillips SD, Gates T. A conceptual framework for understanding the stigmatization of children of incarcerated parents. J Child Fam Stud. 2011;20(3):286-294. doi:10.1007/s10826-010-9391-6

13. Chang K-C, Lin C-Y, Chang -C-C, Ting S-Y, Cheng C-M, Wang J-D. Psychological distress mediated the effects of self-stigma on quality of life in opioid-dependent individuals: a cross-sectional study. PLoS One. 2019;14(2):e0211033. doi:10.1371/journal.pone.0211033

14. Fortney J, Mukherjee S, Curran G, Fortney S, Han X, Booth BM. Factors associated with perceived stigma for alcohol use and treatment among at-risk drinkers. J Behav Health Serv Res. 2004;31 (4):418-429. doi:10.1007/BF02287693

15. Green S, Davis C, Karshmer E, Marsh P, Straight B. Living stigma: the impact of labeling, stereotyping, separation, status loss, and discrimination in the lives of individuals with disabilities and their families. Sociol Inq. 2005;75(2):197-215. doi:10.1111/j.1475-682X.2005.00119.x

16. Mueser KT, Bennett M, Kushner MG. Epidemiology of substance use disorders among persons with chronic mental illnesses; 1995.

17. Hathaway AD, Comeau NC, Erickson PG. Cannabis normalization and stigma: contemporary practices of moral regulation. Criminol Criminal Justice. 2011;11(5):451-469. doi:10.1177/1748895811415345

18. Wrigley S, Jackson H, Judd F, Komiti A. Role of stigma and attitudes toward help-seeking from a general practitioner for mental health problems in a rural town. Aust $N Z J$ Psychiatry. 2005;39 (6):514-521. doi:10.1080/j.1440-1614.2005.01612.x 
19. Ahern J, Stuber J, Galea S. Stigma, discrimination and the health of illicit drug users. Drug Alcohol Depend. 2007;88(2):188-196. doi:10.1016/j.drugalcdep.2006.10.014

20. Gomberg ESL. Alcoholic women in treatment: the question of stigma and age. Alcohol Alcohol. 1988;23(6):507-514.

21. Alonso J, Buron A, Bruffaerts R, et al. Association of perceived stigma and mood and anxiety disorders: results from the World Mental Health Surveys. Acta Psychiatr Scand. 2008;118 (4):305-314. doi:10.1111/j.1600-0447.2008.01241.x

22. Crisp AH, Gelder MG, Rix S, Meltzer HI, Rowlands OJ. Stigmatisation of people with mental illnesses. $\mathrm{Br} J$ Psychiatry. 2000;177(1):4-7. doi:10.1192/bjp.177.1.4

23. Etsedingl Hadera ES, Girma E, Dehning S, Adorjan K, Tesfaye M. Magnitude and associated factors of perceived stigma among adults with mental illness in Ethiopia. Psychiatry J. 2019;2019:9.

24. van Boekel L, Brouwers E, van Weeghel J, Garretsen H. Stigma among health professionals towards patients with substance use disorders and its consequences for healthcare delivery: systematic review. Tijdschr Psychiatr. 2015;57(7):489-497.

25. Alonso J, Buron A, Rojas-Farreras S, et al. Perceived stigma among individuals with common mental disorders. J Affect Disord. 2009;118 (1-3):180-186. doi:10.1016/j.jad.2009.02.006

26. Birtel MD, Wood L, Kempa NJ. Stigma and social support in substance abuse: implications for mental health and well-being. Psychiatry Res. 2017;252:1-8. doi:10.1016/j.psychres.2017.01.097

27. Keyes K, Hatzenbuehler M, McLaughlin K, et al. Stigma and treatment for alcohol disorders in the United States. Am J Epidemiol. 2010;172(12):1364-1372. doi:10.1093/aje/kwq304

28. Aklog GT, Girmay Tsegay T. Assessment of substance abuse and associated factors among students of Debre Markos poly technique college in Debre Markos Town, East Gojjam Zone, Amhara Regional State, Ethiopia, 2013. Glob J Med Res. 2013;13(4).

29. Luoma JB, O'Hair AK, Kohlenberg BS, Hayes SC, Fletcher L. The development and psychometric properties of a new measure of perceived stigma toward substance users. Subst Use Misuse. 2010;45 (1-2):47-57. doi:10.3109/10826080902864712

30. Chang -C-C, Chang K-C, Hou W-L, Yen C-F, Lin C-Y, Potenza MN. Measurement invariance and psychometric properties of Perceived Stigma toward People who use Substances (PSPS) among three types of substance use disorders: heroin, amphetamine, and alcohol. Drug Alcohol Depend. 2020;216:108319. doi:10.1016/ j.drugalcdep.2020.108319
31. Bøen H. Characteristics of senior centre users-and the impact of a group programme on social support and late-life depression. Nor Epidemiol. 2012;22(2). doi:10.5324/nje.v22i2.1574

32. Fekadu A, Medhin G, Selamu M, et al. Population level mental distress in rural Ethiopia. BMC Psychiatry. 2014;14(1):194. doi:10.1186/1471-244X-14-194

33. Filmer D, Pritchett LH. Estimating wealth effects without expenditure data - or tears: an application to educational enrollments in states of India. Demography. 2001;38(1):115-132. doi:10.1353/ dem.2001.0003

34. Stringer KL, Baker EH. Stigma as a barrier to substance abuse treatment among those with unmet need: an analysis of parenthood and marital status. J Fam Issues. 2018;39(1):3-27. doi:10.1177/ 0192513X15581659

35. Van Boekel LC, Brouwers EP, Van Weeghel J, Garretsen HF. Stigma among health professionals towards patients with substance use disorders and its consequences for healthcare delivery: systematic review. Drug Alcohol Depend. 2013;131(1-2):23-35. doi:10.1016/j. drugalcdep.2013.02.018

36. Capezza NM, Zlotnick C, Kohn R, Vicente B, Saldivia S. Perceived discrimination is a potential contributing factor to substance use and mental health problems among primary care patients in Chile. J Addict Med. 2012;6(4):297-303. doi:10.1097/ ADM.0b013e3182664d80

37. Van Nguyen H, Nguyen HLT, Mai HT, et al. Stigmatization among methadone maintenance treatment patients in mountainous areas in northern Vietnam. Harm Reduct J. 2017;14(1):1. doi:10.1186/ s12954-016-0127-9

38. Yang M, Mamy J, Gao P, Xiao S. From abstinence to relapse: a preliminary qualitative study of drug users in a compulsory drug rehabilitation center in Changsha, China. PLoS One. 2015;10(6): e0130711. doi:10.1371/journal.pone.0130711

39. Adlaf EM, Hamilton HA, Wu F, Noh S. Adolescent stigma towards drug addiction: effects of age and drug use behaviour. Addict Behav. 2009;34(4):360-364. doi:10.1016/j.addbeh.2008.11.012

40. James BO, Omoaregba JO, Okogbenin EO. Stigmatising attitudes towards persons with mental illness: a survey of medical students and interns from Southern Nigeria. Ment Illness. 2012;4(1):32-34. doi:10.4081/mi.2012.e8

41. Sarkar S, Balhara YPS, Kumar S, et al. Internalized stigma among patients with substance use disorders at a tertiary care center in India. J Ethn Subst Abuse. 2017;1-14.
Psychology Research and Behavior Management

\section{Publish your work in this journal}

Psychology Research and Behavior Management is an international, peer-reviewed, open access journal focusing on the science of psychology and its application in behavior management to develop improved outcomes in the clinical, educational, sports and business arenas. Specific topics covered in the journal include: Neuroscience, memory and decision making; Behavior modification and management; Clinical applications; Business and sports performance management; Social and developmental studies; Animal studies. The manuscript management system is completely online and includes a very quick and fair peer-review system, which is all easy to use. Visit http://www. dovepress.com/testimonials.php to read real quotes from published authors. 